\title{
cDNA Cloning of Tropomyosin from the Anterior Byssus Retractor Muscle of Mussel and Its Structural Integrity from the Deduced Amino Acid Sequence*1
}

\author{
Keiko Iwasaki, Kiyoshi Kikuchi, Daisuke Funabara, \\ and Shugo Watabe ${ }^{\dagger}$
}

Laboratory of Aquatic Molecular Biology and Biotechnology, Graduate School of Agricultural and Life Sciences, The University of Tokyo, Tokyo 113, Japan

(Received February 6, 1997)

A cDNA clone encoding tropomyosin was isolated from the anterior byssus retractor muscle (ABRM) of the mussel Mytilus edulis galloprovincialis. It contained in total 1,123 nucleotides (nt) with $5^{\prime}$ non-coding $89 \mathrm{nt}, 3^{\prime}$ non-coding $182 \mathrm{nt}$ and coding $852 \mathrm{nt}$ for 284 amino acid residues, a size typical of muscle tropomyosin. Genomic DNA digests with EcoRI, EcoRV and HindIII all exhibited three bands when hybridized with a HaeIII DNA fragment of tropomyosin cDNA, suggesting that the mussel has multiple genes encoding muscle tropomyosin and related proteins. The mRNAs encoding ABRM tropomyosin were most abundant in muscle tissues from byssus retractor and adductor muscles. Considerably large amounts were also observed with gill and inner mantle, whereas traces were found in outer mantle and foot. In the deduced amino acid sequence of ABRM tropomyosin, the N-terminal MDAIKKKMV was well conserved, which has been reported to be involved in head-to-tail polymerization of the tropomyosin molecules. Our tropomyosin was also suggested to have a coiled-coil structure composed of two $\alpha$-helices that showed the heptad repeats $(a-b-c-d-e-f-g)_{n}$ where a and $d$ tended to be occupied by nonpolar residues with further 28-amino acid repeat zones.

Key words: Mitylus edulis galloprovincialis, tropomyosin, cDNA cloning, anterior byssus retractor muscle, amino acid sequence, coiled-coil structure

Tropomyosin, like actin, is one of the most abundant and ubiquitous proteins in muscle and non-muscle cells. Tropomyosin, either from vertebrate muscle, non-muscle or invertebrate tissues, ${ }^{\mathrm{I}-6)}$ is composed of repeating heptads of the form (a-b-c-d-e-f-g) where $a$ and $d$ tend to be nonpolar residues that can form a coiled-coil structure of the two $\alpha$-helices. The $N$-terminal region is critical for tropomyosin to achieve head-to-tail polymerization. ${ }^{7,8)}$ In skeletal muscle, tropomyosin is bound to troponin and subsequently to actin thin filaments, acting as a regulatory component in muscle contraction and relaxation cycle in a $\mathrm{Ca}^{2+}$-dependent manner. ${ }^{9,10)}$ Functions of tropomyosin in invertebrate and smooth muscles are less unambiguous, since their myosin-containing thick filaments are primarily responsible for $\mathrm{Ca}^{2+}$ regulation. ${ }^{11-15)}$

Molluscan adductor muscles are well known to contract for a long time with little energy expenditure. ${ }^{16-18)}$ This phenomenon is called catch and also is typically shown by the anterior byssus retractor muscle (ABRM) of the mussel Mytilus edulis. Although many physiological experiments for catch contraction have been carried out with this ABRM, ${ }^{16,17)}$ much less information is available on the molecular properties of muscle proteins probably due to the extremely small quantities of muscle pieces compared to those of other catch muscles.

The objectives of this study were to isolate a cDNA clone encoding tropomyosin from mussel ABRM, to examine genomic organization and tissue distributions of its transcripts, and to disclose the structural properties from the deduced amino acid sequence. The nucleotide sequence of mussel ABRM tropomyosin itself has recently been recorded in the GenBank nucleotide sequence database by Nyitray et al., ${ }^{* 2}$ but has some variations from our sequence.

\section{Materials and Methods}

\section{Materials}

Live specimens of the mussel Mitylus edulis galloprovincialis $^{19), * 3}$ (average body weight of $24 \mathrm{~g}$ including shells), cultured at the coastal areas of Miyagi Prefecture in the Pacific Ocean, were obtained at the Tokyo Central Wholesale Market. ABRM pieces were carefully dissected while avoiding contamination with visceral parts, immediately frozen with liquid nitrogen, and stored at $-80^{\circ} \mathrm{C}$ until use.

\footnotetext{
" The DNA nucleotide sequence data in this paper will appear in the DDBJ, EMBL and GenBank nucleotide sequence databases with the following accession number AB000907.

$\dagger$ To whom all correspondence should be addressed.

${ }^{*} 2$ The GenBank nucleotide sequence database with accession No. U40035 registered by L. Nyitray, W. Yang, and A. G. Szent-Gyorgyi (1995).

*3 Personal communication from $\mathrm{K}$. Inoue.
} 


\section{Construction of cDNA Library}

Total RNA was prepared from $7 \mathrm{~g}$ of ABRM corresponding to 100 mussel specimens by the method of Chomczynski and Sacchi. ${ }^{20)}$ Poly $(\mathrm{A})^{+}$mRNA was isolated from total RNA using an oligo d(T) ${ }^{+}$cellulose column (Pharmacia) ${ }^{21)}$ Five $\mu \mathrm{g}$ of mRNA were used for double-stranded cDNA synthesis, which was carried out using Pharmacia cDNA synthesis kits with an oligo dT primer. The cDNA library was constructed using synthesized cDNAs in a phage vector $\lambda$ ZAP II according to the supplier's instructions (Stratagene), after ligating cDNA to a Not I/EcoRI linker.

\section{cDNA Cloning}

Polyclonal antibody raised against paramyosin from the adductor muscle of hard clam Meretrix meretrix ${ }^{22)}$ was used for screening. This antibody has been found to react with both paramyosin and tropomyosin (data not shown). Positives were plaque purified, and the inserts were excised in the form of pBluescript SK plasmid vectors according to the manufacturer's protocol. The plasmid DNAs were purified by an alkaline lysis method ${ }^{21)}$ and used for DNA sequence analysis. Positive clones encoded only tropomyosin but no paramyosin.

\section{Sequencing Analysis}

DNA sequencing was carried out for both strands on subclones with a Perkin Elmer/Applied Biosystems model 373A DNA sequencer after labeling with Taq dye deoxy terminator cycle sequencing kits. The protein homology search was performed by using the SWISS-PROT protein sequence database coordinated with the Inherit program (Perkin Elmer/Applied Biosystems).

\section{Southern Blot Analysis}

Genomic DNA was isolated by homogenizing the hepatopancreas and subsequently treating with proteinase K. ${ }^{21)}$ For Southern blot analysis, $10 \mu \mathrm{g}$ of genomic DNAs were digested with a series of restriction endonucleases and electrophoresed in $0.7 \%$ agarose gels. The gels were processed with slight modifications after Sambrook et al. ${ }^{21)}$ denatured with $0.5 \mathrm{M} \mathrm{NaOH}$ containing $1.5 \mathrm{M} \mathrm{NaCl}$, transferred to Hybond $\mathrm{N}^{+}$nylon membranes (Amersham) omitting renaturing steps, and baked at $80^{\circ} \mathrm{C}$ for $15 \mathrm{~min}$. The membranes were hybridized at $65^{\circ} \mathrm{C}$ in $0.5 \mathrm{M} \mathrm{NaHPO}_{4}$ (pH 7.2) containing $1 \mathrm{mM}$ EDTA and $7 \% \operatorname{SDS}^{23)}$ with a ${ }^{32} \mathrm{P}$-labeled DNA fragment obtained by HaeIII digestion of tropomyosin cDNA. Membrane filters were washed at $65^{\circ} \mathrm{C}$ with several buffer changes of decreasing SSC concentrations from $5 \times$ to $0.1 \times$ and autoradiographed on $\mathrm{x}$-ray films with intensifying screens at $-80^{\circ} \mathrm{C}$.

\section{Northern Blot Analysis}

Ten $\mu \mathrm{g}$ of total RNAs isolated from various tissues of the mussel were denatured at $65^{\circ} \mathrm{C}$ for $15 \mathrm{~min}$ in $50 \%$ formamide, subjected to electrophoresis on a $0.9 \%$ agarose gel in $0.04 \mathrm{M}$ MOPS ( $\mathrm{pH} 7.0$ ) containing $0.44 \mathrm{M}$ formamide, $0.01 \mathrm{M}$ sodium acetate and $1 \mathrm{mM}$ EDTA, and transferred to nylon membranes. The membranes were airdried and baked at $80^{\circ} \mathrm{C}$ for 15 min prior to hybridization. The following procedures for hybridization and autoradiography were carried out as those for Southern blot analysis.

\section{Results and Discussion}

\section{cDNA Cloning}

Our primary attempt to isolate a paramyosin cDNA clone from ABRM of $M$. edulis galloprovincialis was not successful with the polyclonal antibody raised against paramyosin from hard clam $M$. meretrix. ${ }^{22)}$ Since the antibody was reacted with not only paramyosin but also tropomyosin (data not shown), we could fortunately clone cDNA encoding tropomyosin. From about $5 \times 10^{4}$ plaques, 8 positive clones were obtained. DNA sequence analysis after subcloning revealed that all clones were found to encode tropomyosin by homology research with Inherit analysis. The clone having the longest DNA length contained in total 1,123 nucleotides (nt) with $5^{\prime}$ non-coding $89 \mathrm{nt}, 3^{\prime}$ non-coding $182 \mathrm{nt}$, and coding $852 \mathrm{nt}$ for 284 amino acid residues, a size typical of muscle tropomyosin. However, no polyadenylation signal has been found so far. When compared with the DNA nucleotide sequence reported by Nyitray et al. (refer to "Introduction") for $M$. edulis ABRM, our sequence from $M$. edulis galloprovincialis contained three nucleotide variations, resulting in one amino acid substitution of 250-Arg to our Gln. These differences might be caused by genetic variations of Mytilus subspecies. ${ }^{19)}$

\section{Southern Blot Analysis}

Genomic DNA was obtained from the hepatopancreas of $M$. edulis galloprovincialis and digested with various endonucleases including EcoRI, EcoRV, HindIII and BamHI. Digests were size-fractionated by agarose-gel electrophoresis and transferred onto nylon membranes, followed by hybridization with a ${ }^{32} \mathrm{P}$-labeled DNA fragment obtained by HaelII digestion of tropomyosin cDNA. This fragment encoded $5^{\prime}$-terminal $199 \mathrm{nt}$ of the translated region and was selected due to a low possibility to extend over two exons containing an intron between them by referring to the data reported for the tropomyosin gene of Caenorhabditis elegans. ${ }^{6}$ Genomic DNA digests with $E c o$ RI, EcoRV and HindIII all contained three hybridized bands, whereas BamHI digests exhibited two bands (Fig. 1). These results suggest a possibility that the mussel has multiple genes encoding muscle tropomyosin and related proteins. Further analysis will reveal details of the genomic organization of mussel tropomyosin.

\section{Northern Blot Analysis}

Total RNA was prepared from various tissues of $M$. edulis galloprovincialis including ABRM, posterior byssus retractor muscle, adductor muscle, gill, foot, outer mantle and inner mantle. Ten mg each of RNA preparations were subjected to agarose-gel electrophoresis under denaturing conditions and hybridized with the same DNA probe as that used for Southern blot analysis. The two larger $r R$ NAs (18S and 26S) ${ }^{24)}$ were used as the molecular weight markers after staining with ethidium bromide. The $\mathrm{mR}$ NAs encoding ABRM tropomyosin were most abundant in muscle tissues from byssus retractor and adductor muscles (Fig. 2). However, considerably large amounts were also observed with gill and inner mantle where any con- 


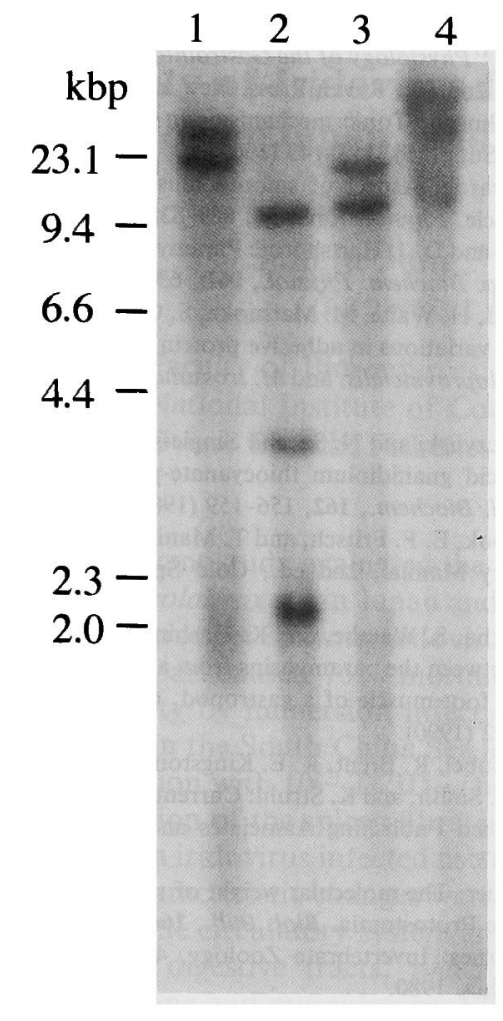

Fig. 1. Southern blot analysis for genomic organization of tropomyo$\sin$ from the anterior byssus retractor muscle of Mytilus edulis galloprovincialis.

Genomic DNA was prepared from the hepatopancreas and digested with various endonucleases including EcoRI (lane 1), EcoRV (lane 2), HindIII (lane 3) and BamHI (lane 4). A DNA fragment obtained by HaeIII digestion of tropomyosin cDNA was ${ }^{32} \mathrm{P}$-labeled and used as a probe.

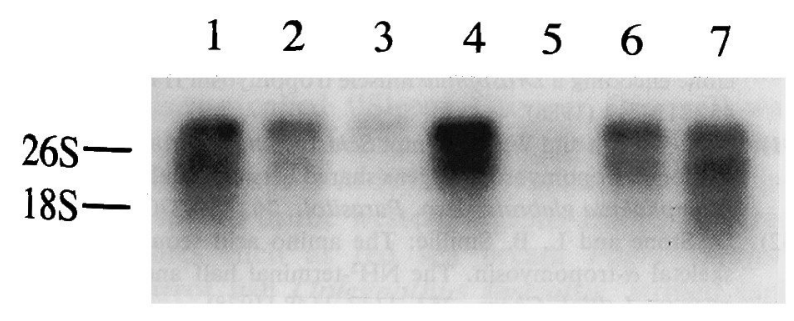

Fig. 2. Northern blot analysis for tropomyosin from the anterior byssus retractor muscle of Mytilus edulis galloprovincialis in various tissues.

Total RNA was isolated from various tissues including anterior byssus retractor muscle (lane 1), gill (lane 2), foot (lane 3), posterior byssus retractor muscle (lane 4 ), outer mantle (lane 5), inner mantle (lane 6) and adductor muscle (lane 7). Refer to the legend of Fig. 1 for the probe.

tamination with muscle tissues was avoided as much as possible. In addition, traces of tropomyosin transcripts were found in foot and outer mantle. It should be noted that mussel has an evolutionarily reduced foot function, since adult mussel has no need to crawl at the bottom of the sea, but rather attaches to rocks or climbs vertical walls with

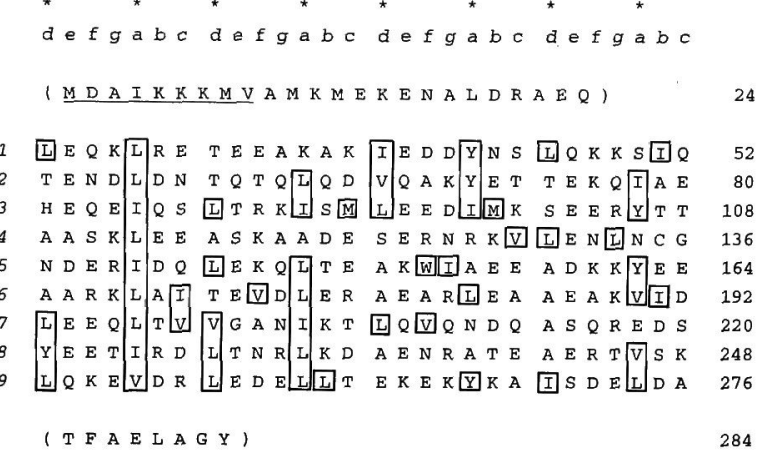

Fig. 3. Amino acid sequence of tropomyosin from the anterior byssus retractor muscle of Mytilus edulis galloprovincialis arranged in 28residue repeat zones.

The positions of $\mathrm{d}, \mathrm{e}, \mathrm{f}, \mathrm{g}, \mathrm{a}, \mathrm{b}$ and $\mathrm{c}$ of the 7-residue coiled-coil repeat are marked above the columns, where supposed positions for hydrophobic amino acids, a and $\mathrm{d}$, are indicated with asterisks. Hydrophobic amino acid residues in trompomyosin are boxed. The $\mathrm{N}$-terminal region responsible for end-to-end overlaps of the tropomyosin molecules to polymerize is underlined. The $\mathrm{N}$ - and $\mathrm{C}$ terminal regions in parentheses are not included in the 28-residue repeat zones.

byssus threads at the seashore. ${ }^{25)}$ In any tissues of $M$. edulis galloprovincialis except for foot, two hybridized bands were observed. However, no clones encoding different tropomyosin isoforms have been found so far. Since no polyadenylation signal was detected in our clones, we did not consider the presence of multiple sites of such signal. The unexpected low mobility of mRNAs encoding tropomyosin in agarose gel electrophoresis for Northern blot analysis compared to the size of cDNAs cloned was possibly due to the deletion of the $3^{\prime}$ non-coding region including poly A tail in our clones during construction of the cDNA library. Vertebrate skeletal muscles contain varying compositions of $\alpha$ - and $\beta$-tropomyosin isoforms having 284 amino acid residues. ${ }^{26,27)}$ In non-muscle tissues, however, the tropomyosin isoform is usually smaller in amino acid residue numbers. ${ }^{3,5,28,29)}$ The occurrence of tropomyosin isoforms for molluscan tissues is not clear at present. Further attempts at genomic cloning will clarify such ambiguities.

\section{Coiled-coil Structure of Two $\alpha$-Helices}

The present tropomyosin showed low homology in amino acid sequence to muscle-type tropomyosins from other sources including Drosophila melanogaster type $\mathrm{II}^{30}$ ) Schistosoma mansoni, ${ }^{31)}$ rabbit $\alpha$-type ${ }^{32)}$ and human $\alpha$ type $^{33)}$ with $39,53,37$ and $38 \%$ identity, respectively. However, the N-terminal amino acid sequence of MDAIKKKMV (Fig. 3) was well conserved, which is involved in head-to-tail polymerization of the tropomyosin molecules. ${ }^{8)}$ Scallop adductor muscle tropomyosin has also been reported to polymerize in the absence of neutral salt. ${ }^{34)}$

It is well known that tropomyosins either from muscle or non-muscle tissues contain a coiled-coil structure composed of two $\alpha$-helices. ${ }^{1-6)}$ Such proteins usually have the heptad repeats (a-b-c-d-e-f-g) $)_{n}$ where $a$ and $d$ tend to be oc- 
cupied by nonpolar residues. This pattern produces a hydrophobic seam along one side of each helix and the two helices join into the coiled-coil structure along this seam. Figure 3 shows the deduced amino acid sequence of the present ABRM tropomyosin with the heptad repeats. These heptad repeats were arranged into nine repeat zones of the 28-amino acid unit, but contained no skip residues even after the best alignment unlike myosin rod $^{35,36)}$ or paramyosin $^{37)}$ from other sources.

Mytilus ABRM is a typical catch muscle and its physiological aspects have been studied extensively. ${ }^{16,17)}$ This paper revealed the primary structure of ABRM tropomyosin. Further analysis on other myofibrillar proteins such as paramyosin and myosin will clarify the mechanisms involved in the regulation of molluscan catch contraction and relaxation cycle that is dependent on $\mathrm{Ca}^{2+}$ and cAMP. ${ }^{18)}$

Acknowledgments The present study was partly supported by a Grantin-Aid from the Ministry of Education, Science, Sports and Culture of Japan.

\section{References}

1) A. D. McLachlan, M. Stewart, and L. B. Smillie: Sequence repeats in $\alpha$-tropomyosin. J. Mol. Biol., 98, 281-291 (1975).

2) G. S. Basi and R. V. Storti: Structure and DNA sequence of the tropomyosin I gene from Drosophila melanogaster. J. Biol. Chem. 261, 817-827 (1986).

3) M. K. Balasubramanian, D. M. Helfman, and S. M. Hemmingsen A new tropomyosin essential for cytokinesis in the fission yeast $S$. pombe. Nature, 360, 84-87 (1992).

4) C. D. Baader, V. Schmid, and P. Schuchert: Characterization of a tropomyosin cDNA from the hydrozoan Podocoryne carnea. FEBS Lett., 328, 63-66 (1993).

5) H. $\mathrm{X}_{\mathrm{u}}, \mathrm{S}$. Miller, H. van Keulen, M. R. Wawrzynski, D. M Rekosh, and P. T. LoVerde: Schistosoma mansoni tropomyosin: cDNA characterization, sequence, expression, and gene product localization. Exp. Parasitol., 69, 373-392 (1989).

6) H. Kagawa, K. Sugimoto, H. Matsumoto, T. Inoue, H. Imadzu, K Takuwa, and Y. Sakube: Genome structure, mapping and expression of the tropomyosin gene tmy- 1 of Caenorhabditis elegans. $J$, Mol. Biol., 251, 603-613 (1995)

7) R. S. Hodges, J. Sodek, L. B. Smillie, and L. Jurasek: Tropomyosin: amino acid sequence and coiled-coil structure. Cold Spring Harbor Symp. Quant. Biol., 37, 299-310 (1972).

8) A. D. McLachlan and M. Stewart: Tropomyosin coiled-coil interactions: evidence for an unstaggered structure. J. Mol. Biol., 98, 293304 (1975).

9) S. Ebashi and M. Endo: Calcium ion and muscle contraction. Prog, Biophys. Mol. Biol., 18, 123-183 (1968).

10) I. Ohtsuki, K. Maruyama, and S. Ebashi: Regulatory and cytoskeletal proteins of vertebrate skeletal muscle. $A d \nu$. Prot. Chem., 38, 2579-2583 (1986).

11) A. G. Szent-Gyorgyi, E. M. Szentkiralyi, and J. Kendrick-Jones: The light chains of scallop myosin as regulatory subunits. $J$. Mol. Biol., 74, 179-203 (1973).

12) J. Kendrick-Jones, E. M. Szentkiralyi, and A. G. Szent-Gyorgyi: Regulatory light chains in myosins. J. Mol. Biol., 104, 747-775 (1976).

13) T. Ojima, K. Nishita, and S. Watanabe: Akazara scallop myosins hybridized with DTNB-light chains of skeletal myosin and with regulatory light chains of gizzard myosin. J. Biochem., 94, 307-310 (1983).

14) K. Konno, K. Arai, and S. Watanabe: Myosin-linked calcium regulation in squid mantle muscle. Light-chain components of squid myosin. J, Biochem., 86, 1639-1650 (1979).
15) D. J. Hartshorne: Biochemistry of the contractile process in smooth muscle, in "Physiology of the Gastrointestinal Tract" (ed. by L. R. Johnson), 2nd ed., Raven Press, New York, 1987, pp. 423-482.

16) W. H. Johnson: Tonic mechanisms in smooth muscles. Physiol. Rev., 42 (Suppl. 5), 113-143 (1962).

17) B. M. Twarog: Aspect of smooth muscle function in molluscan catch muscle. Physiol. Rev., 56, 829-838 (1976).

18) S. Watabe and D. J. Hartshorne: Paramyosin and the catch mechanism. Comp. Biochem. Physiol., 96B, 639-646 (1990).

19) K. Inoue, J. H. Waite, M. Matsuoka, S. Odo, and S. Harayama: In terspecific variations in adhesive protein sequences of Mytilus edu lis, M. galloprovincialis, and M. trossulus. Biol. Bull., 189, 370-375 (1995).

20) P. Chomiczynski and N. Sacchi: Single-step method of RNA isolation by acid guanidinium thiocyanate-phenol-chloroform extraction. Anal. Biochem., 162, 156-159 (1987).

21) J. Sambrook, E. F. Fritsch, and T. Maniatis: Molecular Cloning. A Laboratory Manual, 2nd ed., Cold Spring Harbor, New York, 1989.

22) S. SriKantha, S. Watabe, and K. Hashimoto: Immunological comparison between the paramyosins from adductor muscle of bivalves and from foot muscle of a gastropod. Comp. Biochem. Physiol., 96B, 89-92 (1990).

23) F. M. Ausubel, R. Brent, R. E. Kingston, D. D. Moore, J. G. Seidman, J. A. Smith, and K. Struhl: Current Protocols in Molecular Biology, Green Publishing Associates and Wiley-Interscience, New. York, 1987.

24) J. R. Collier: The molecular weight of ribosomal ribonucleic acids among the Protostomia. Biol. Bull., 164, 428-432 (1983).

25) R. D. Barnes: Invertebrate Zoology, 4th ed., Saunders College, Philadelphia, 1980.

26) P. Cummins and S. V. Perry: Chemical and immunochemical characteristics of tropomyosins from striated and smooth muscle. Biochem. J., 141, 43-49 (1974).

27) J. P. Lees-Miller and D. M. Helfman: The molecular basis for tropomyosin isoform diversity. BioEssays, 13, 429-437 (1991).

28) P. D. Hanke, H. M. Lepinske, and R. V. Storti: Characterization of a Drosophila cDNA clone that encodes a 252-amino acid nonmuscle tropomyosin isoform. J. Biol. Chem., 262, 17370-17373 (1987).

29) K. Miyado, M. Katsuki, and S. Taniguchi: Isolation of a yeast tropomyosin-related cDNA clone that encodes a novel transmembrane protein having a $C$-terminal highly basic region. Biochem. Biophys. Res. Commun., 199, 1363-1371 (1994).

30) P. D. Hanke and R. V. Storti: Nucleotide sequence of a cDNA clone encoding a Drosophila muscle tropomyosin II isoform. Gene, 45, 211-214 (1986).

31) D. S. Weston and W. M. Kemp: Schistosoma mansoni: comparison of cloned tropomyosin antigens shared between adult parasites and Biomphalaria glabrata. Exp. Parasitol., 76, 358-370 (1993).

32) D. Stone and L. B. Smillie: The amino acid sequence of rabbit skeletal $\alpha$-tropomyosin. The $\mathrm{NH}^{2}$-terminal half and complete sequence. J. Biol. Chem., 253, 1137-1148 (1978).

33) S. M. Mische, B. N. Manjula, and V. A. Fischetti: Relation of streptococcal $\mathrm{M}$ protein with human and rabbit tropomyosin: the complete amino acid sequence of human cardiac alpha tropomyosin, a highly conserved contractile protein. Biochem. Biophys. Res. Commun., 142, 813-818 (1987).

34) S. Watabe and K. Hashimoto: Isolation and characterization of scallop smooth adductor tropomyosin. Nippon Suisan Gakkaishi, 46, 1183-1188 (1980).

35) A. D. McLachlan and J. Karn: Periodic charge distributions in the myosin rod amino acid sequence match cross-bridge spacings in muscle. Nature, 299, 226-231 (1982).

36) G. Offer: Skip residues correlate with bends in the myosin tail. $J$. Mol. Biol., 216, 213-218 (1990).

37) H. Kagawa and K. Gengyo: Paramyosin gene (unc-15) of Caenorhabditis elegans. Molecular cloning, nucleotide sequence and models for thick filament structure. J. Mol. Biol., 207, 311-333 (1989). 